\title{
Integrated ultra-thin-film gas sensors
}

\author{
C.L. Johnson* and J.W. Schwank \\ Deparment of Chemical Engineering, University of Michigan, Ann Ahor, MI 48109-2103 (USA) \\ K.D. Wise \\ Department of Flectrical Engineering and Computer Science, University of Michigan, Ann Arbor, MI $48109-2122$ (USA)
}

(Received May 18, 1992; in revised form August 6, 1993; accepted September 10, 1993)

\begin{abstract}
The fabrication and performance of an ultra-thin-film integrated gas sensor for detecting impurities in semiconductor process gases are described. Detector responses are based on gas-induced resistance changes in an ultra-thin Ti-P film mounted on a thin dielectric window supported by a silicon rim. The window temperature can be shifted several hundred degrees Celsius in less than one second. Gas-induced resistance changes are composed of thermal and chemical components. The gas concentration and its thermal conductivity determine the thermal contribution, whereas the chemical interactions between the gas and the sensor surface create a superimposed change of resistance, which can be observed when the detector is operated at constant temperature. Pretreatment of the as-deposited Ti-Pt thin films under controlled environmental conditions allows tailoring of the electrical, sensing, and microstructural characteristics of the films. One such pretreatment scheme allows the creation of films that, when operated at $150^{\circ} \mathrm{C}$, respond chemically to $\mathrm{O}_{2}$ from 1000 torr down to the $10^{-7}$ torr level without any evidence of hysteresis or long-term drift over hundreds of cycles of temperature and gas. There is no chemical response to $\mathrm{CF}_{4}$, which allows detection of sub-ppm levels of $\mathrm{O}_{2}$ in $\mathrm{CF}_{4}$. Temperature-programmed desorption (TPD) of $\mathrm{O}_{2}$ is shown to be a control requirement for dynamic sensing.
\end{abstract}

\section{Introduction}

High process cost and chip complexity are driving increased levels of semiconductor process equipment automation in order to effect the rapid and accurate real-time evaluation of tool and wafer diagnostic information. Such automation requires complex distributed sensing systems with appropriate detectors targeting the parameters of interest. One of the key parameters to be controlled is the composition of semiconductor process gases, with particular emphasis on gas purity.

Among the many possible methods for gas detection, solid-state gas sensors appear promising due to their potential for high sensitivity at relatively low cost. However, present solid-state gas detectors have a number of shortcomings, ranging from insufficient sensitivity and selectivity to the time-related problems of slow response, long-term drift, irreversibility, and hysteresis. There are inherent difficulties in controlling gas-detector interactions, which are compounded by

\footnotetext{
*Present address: IBM Corporation, Burlington, VT 054522199, USA.
}

the multi-variant analyses required to deconvolute the resulting electrical signals.

Improvement in these characteristics requires films that interact with targeted gases in a predictable and desirable way based upon previously observed mechanistic behavior. For example, in the case of conventional continuous metal gate chemFETs $[1,2]$, Pd-gate MOS devices respond to $\mathrm{H}_{2}$ faster and with greater sensitivity than MOS devices with other gate metals (see, e.g., ref. 3). This observed difference is mechanistic; it is well known that $\mathrm{H}_{2}$ diffuses through $\mathrm{Pd}$ but not through other metals. Devices with discontinuous metal gates not unexpectedly exhibit an enhanced response not only to hydrogen but to a variety of other gases as well [4-9]. Some of the chemFET pioneers have also extended these principles in interesting ways, such as applying a pulsed light beam to generate a photocapacitive current that varies with the surface potential of an array of discontinuous films [10].

Among the critical considerations in film selection is the reversibility of the response mechanism. Clearly, irreversible reactions between the transducing film and the gas should be avoided to ensure long-term stability in the environment of interest. Thus, one set of possible 
transducing film candidates is the metal catalyst family, since catalysts increase reaction rates but are not consumed during the reaction itself. This paper describes the use of ultra-thin (100 $\AA$ or less), preferably discontinuous, metal films for gas detection. The targeted mechanism is reversible gas adsorption, leading to gasspecific film conductivity changes.

\section{Detector design and fabrication}

The selected detection films were incorporated into a silicon-based transducing structure. The structure described is a modified version of one described elsewhere [11]. In this version, the thin transducing film resides on top of a $1.3 \mathrm{~mm}$ square, $1.3 \mu \mathrm{m}$ thick dielectric window of $\mathrm{SiO}_{2}, \mathrm{Si}_{3} \mathrm{~N}_{4}, \mathrm{SiO}_{2}$, micromachined in a silicon wafer as shown in Figs. 1 and 2. The layered dielectric structure provides stress compensation for improved window integrity. A $5 \mu \mathrm{m}$ thick meandering deep borondiffused heater under the window allows heating to temperatures above $1000{ }^{\circ} \mathrm{C}$ with a time constant of about $15 \mathrm{~ms}$ and does not compromise the planarity of the dielectric window. Additional structures include thermocouples and thermopiles for independent tem-

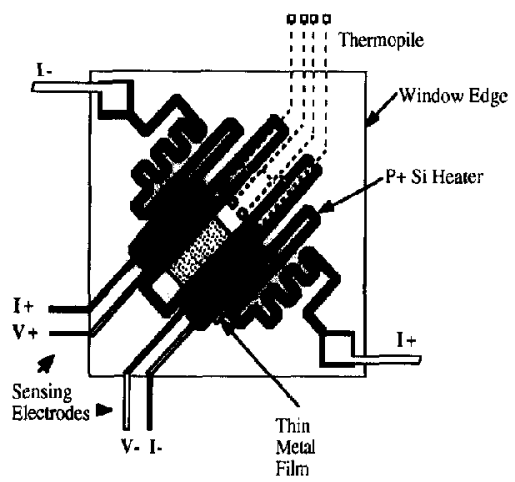

Fig. 1. Top view of the detector window with meandering heater, thin metal transducing film with associated electrodes, and thermopile structure. The window measures $1.3 \mathrm{~mm} \times 1.3 \mathrm{~mm}$.

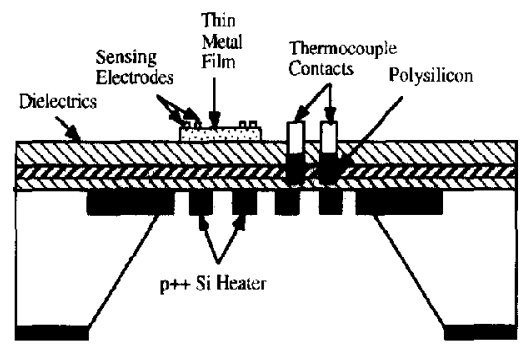

Fig. 2. Cross-sectional view of monolithic gas detector. The typical thicknesses of the dielectric window, the boron-diffused heater, and the overall silicon substrate are $1.3,5$ and $300 \mu \mathrm{m}$, respectively. perature evaluation, contact resistance measurement structures, and various detecting film geometries to explore possible correlations between gas sensitivity and transducing film surface area. A $300 \mu \mathrm{m}$ thick silicon rim provides structural stability to the devices.

The detector fabrication process begins with a $1175^{\circ} \mathrm{C}$ solid-source boron diffusion into a silicon wafer masked by a patterned oxide. This diffusion defines the heater and the silicon rim area on the front and the final window area and chip dimensions on the back. This patterned oxide is removed, and a thermal oxide is grown, followed by polysilicon deposition, doping, and patterning for the thermocouple and thermopile structures. Films of LPCVD $\mathrm{Si}_{3} \mathrm{~N}_{4}$ and $\mathrm{SiO}_{2}$ complete the dielectric window stack. A buffered HF etch and an r.f. plasma etch open contacts through the $\mathrm{SiO}_{2}$ and $\mathrm{Si}_{3} \mathrm{~N}_{4}$ to the buried heater and the thermocouples. An ultra-thin film, in this case $65 \AA$ Ti and $35 \AA \mathrm{Pt}$, is then evaporated and subsequently lifted off outside the lithographically defined thin-film area. Similarly, films of $200 \AA \mathrm{Ti}$ and $1500 \AA$ Ir are sputtered and lifted off to define the sensing and thermocouple electrode regions. Additional metal layers of $\mathrm{Ti}$ and $\mathrm{Au}$ are placed in the external pad areas to improve Au wire bonding. Gold is not used in the interior of the device, since the robust boron-diffused heater allows heating well above the $\mathrm{Au}-\mathrm{Si}$ eutectic temperature of $377^{\circ} \mathrm{C}$. Photographs of the fabricated detector are shown in Fig. 3.

\section{Detector test system}

A custom-built vacuum system, interface circuit, and automated test system were designed and constructed for reproducible detector characterization (Fig. 4). The vacuum system, supported by a Balzers turbomechanical pump, had a base pressure of $10^{-8}$ torr. A $1.33^{\prime \prime}$ stainlesssteel testing chamber was connected to a rack of test gases, the turbomechanical pump, and a VG Instruments mass analyzer. The sensor was mounted on a 10-pin electrical feedthrough connected to an external interface circuit. An ionization gauge, a 1 torr Baratron gauge, and a 1000 torr Baratron gauge measured pressure in the system. The mass analyzer was placed so that the background gases, the gases in the testing chamber, or the feed gases could be analyzed.

The interface circuit provided an a.c. or d.c. signal to the transducing film and the corresponding outputs (D/A) were amplified and sent to the data-acquisition system. The d.c. portion of the interface circuit (Fig. 4) compared a known resistance $R_{\mathrm{L}}$ and an unknown transducing film resistance, $R_{\mathrm{x}}$. The $R_{\mathrm{D} 1}$ and $R_{\mathrm{D} 2}$ values were set at $2.5 \mathrm{k} \Omega$ and $100 \Omega$, respectively. In these experiments, only d.c. measurements were taken. 


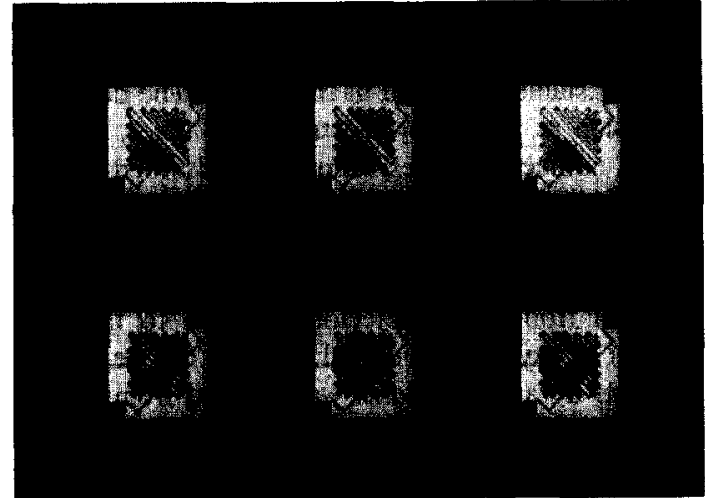

(a)

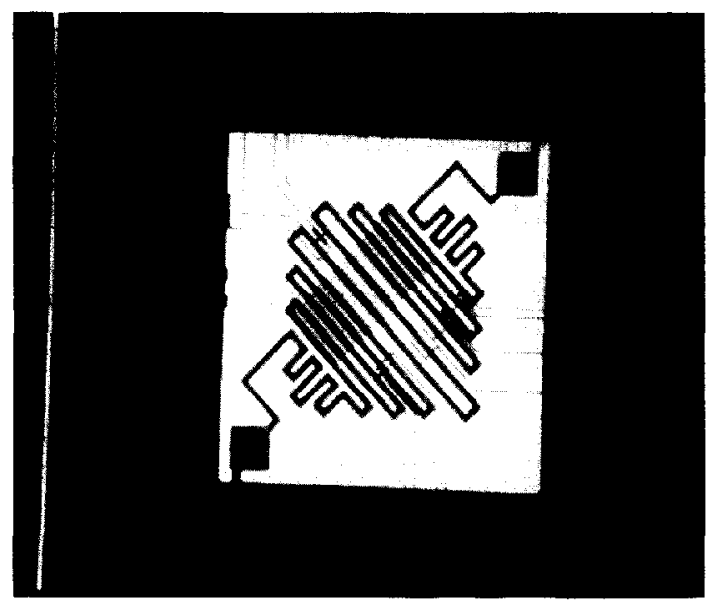

(b)

Fig. 3. Photograph of an array of detectors (above) and a single device in transmitted and reflected light. The overall chip is $2.875 \mathrm{~mm}$ on a side.

Dynamic proportional-integral heater control was achieved via GPIB interfacing to an IBM PC/XT computer, and temperature overshoot was minimized to prevent the accidental desorption of any species of interest. Sudden pressure drops greater than a few orders of magnitude caused control problems, since the resultant temperature changes occurred far more rapidly than the data-acquisition turn-around time for a single measurement. Data-acquisition speed was limited by the computer-controlled gain adjustments applied to the ranging amplifier, $\mathrm{A}_{3}$. Smaller pressure changes, faster data acquisition, or an appropriately placed pressure sensor to detect large impending pressure changes would alleviate this temperature-control problem.

\section{Detector characterization}

The average boron-diffused heater resistance was 585 $\Omega$ with an average temperature coefficient of resistance
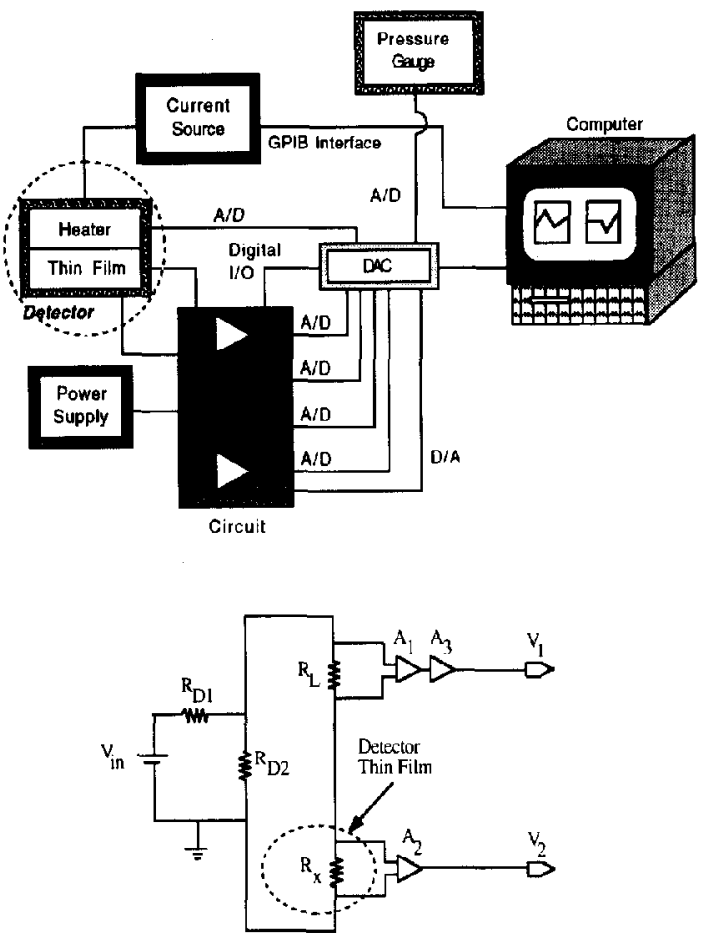

Fig. 4. Schematic of the overall test system (above) and the d.c. portion of the detector interface circuit.

of $1573 \mathrm{ppm} / / \mathrm{C}$. The heaters can be operated either at a fixed heater current or at a constant temperature. In the constant-heater-current mode, the thin-film resistance change induced by the presence of gas contains both a thermal and a chemical component. Alternatively, in constant-temperature mode, the heater current required to maintain the fixed temperature indicates the thermal component, whereas the thin-film resistance change corresponds to the non-thermal, or chemical, component. The nomenclature 'chemical component' would be slightly inaccurate for the case of a strongly endothermic or exothermic reaction between gas and sensor surface, because such a reaction would be incorporated into the thermal component despite being chemical in nature.

A comparison of the heater-control modes is depicted in Fig. 5 for the case of $\mathrm{CF}_{4}$. The detector only responds thermally to $\mathrm{CF}_{4}$ since there is a response at fixed heater current (chemical and thermal components) but not at fixed temperature (chemical component only). The same quantities of differing species do not respond identically; in fact, the differences are related to the thermal conductivity of the gases present. The detector will sense virtually all gas species even if they are chemically inert to the film chosen. For a given species, the required heater current is a function of the gas pressure and the chosen temperature. An example for 


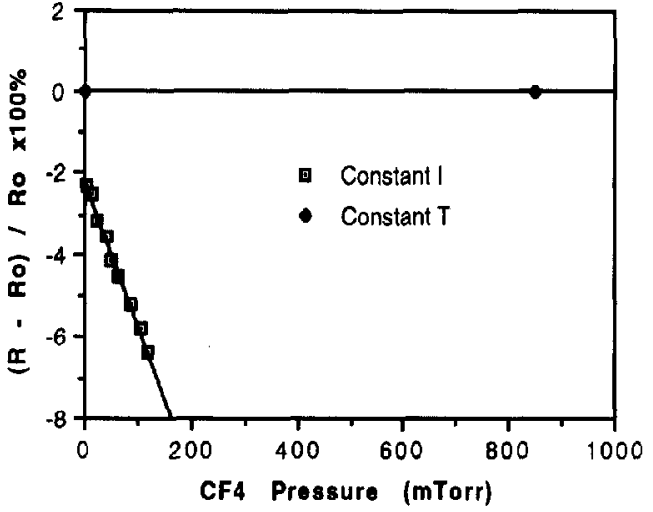

Fig. 5. Percentage resistance change at constant heater current and constant window temperature vs. $\mathrm{CF}_{4}$ pressure for a typical monolithic gas detector.

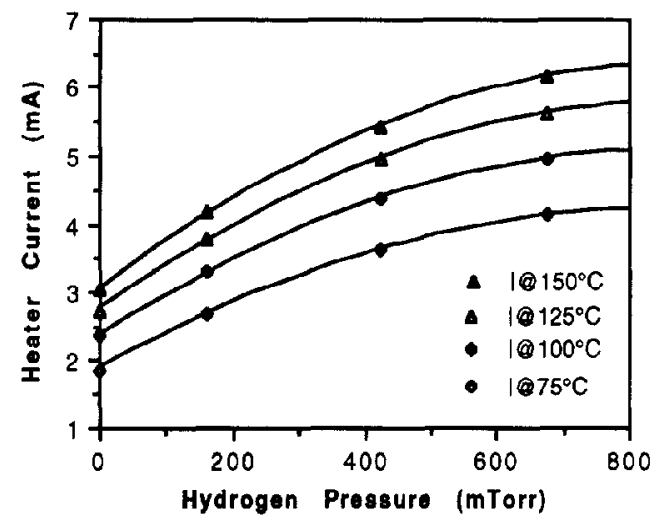

Fig. 6. Heater current at various temperature vs. $\mathrm{H}_{2}$ pressure.

the case of hydrogen is shown in Fig. 6. For a fixed temperature, the heater current is adjusted depending upon the desired temperature, the species type, and the quantity of gas. While the thermal response provides some information on the gaseous species present, the thermal conductivities are not additive and are difficult to deconvolve if multiple gas species are present.

The resistance of the as-deposited thin film ranged from 189 to $249 \Omega$. With behavior paralleling that of conventional catalysts, the detector performance was enhanced by a stabilizing pretreatment. The pretreatment aim was dispersion of the metals into island-like structures to increase the film resistance and the available surface area for adsorption, thereby targeting a response time and sensitivity enhancement. In order to effect this change, cycles of $\mathrm{H}_{2}$ and $\mathrm{O}_{2}$ were used to alternately reduce and oxidize the Pt film, which is known to increase Pt dispersion. The amount of adsorbed oxygen deliberately allowed to remain on the surface after the last oxygen cycle was also a pretreatment variable. The final step involved a rapid high- temperature treatment in various oxygen concentrations. This treatment step also defined the upper temperature limit for stable operation of the device. The degree of dispersion as judged by the treatment times, temperatures, number of cycles, amount of adsorbed oxygen, along with the conditions of the final treatment step influenced both the final resistance and temperature coefficient of resistance. The best performance was obtained from those detectors exposed to the least amount of oxygen in the final step. As can be seen in Table 1, a variety of films was created from the asdeposited Pt-on-Ti combination during experiments to determine the optimum pretreatment procedure. Some of the detectors shown in this Table were further treated after these measurements; two intermediate values of detector $G$ are shown, for example. Table 2 shows qualitatively the role of oxygen in the final film characteristics.

The relatively large nominal film thickness of $100 \AA$ ensured good contact between the sensing films and the substantially thicker sensing electrodes. Films thin-

TABLE 1. Resistances and temperature coefficients of pretreated films of $65 \AA \mathrm{Ti}$ plus $35 \AA \mathrm{Pt}$

\begin{tabular}{llc}
\hline Sensor & $\begin{array}{l}\text { Resistance } \\
(\Omega)\end{array}$ & $\begin{array}{l}\text { TCR } \\
(\mathrm{ppm} / \mathrm{C})\end{array}$ \\
\hline A & $189^{2}$ & +360 \\
A & 400 & +288 \\
D & 356 & -118 \\
B & 425 & +94 \\
G & 824 & +701 \\
G & 2173 & +863 \\
F & 4539 & +771 \\
\hline
\end{tabular}

"Untreated case.

TABLE 2. Pretreatment role of oxygen on the final electrical characteristics of the detectors 'Environment' refers to the amount of background oxygen present during the final pretreatment phase. Note that the TCR value for F went from positive 771 to negative 766 with additional treatment in mtorr-range oxygen

\begin{tabular}{llcc}
\hline Sensor & Environment & $\begin{array}{l}\text { Resistance } \\
(\mathbf{\Omega})\end{array}$ & $\begin{array}{l}\text { TCR } \\
\left(\mathrm{Ppm} /{ }^{\circ} \mathrm{C}\right)\end{array}$ \\
\hline $\mathrm{B}$ & high vacuum & 423 & +85 \\
$\mathrm{D}$ & atmospheric air & 356 & -251 \\
$\mathrm{~F}^{\mathrm{a}}$ & mtorr-range $\mathrm{O}_{2}$ & 3298 & -766 \\
\hline Sensor & Adsorbed $\mathrm{O}_{2}$ & Resistance & \multicolumn{1}{c}{$\mathrm{TCR}$} \\
& & $(\Omega)$ & $\left(\mathrm{Ppm} /{ }^{\circ} \mathrm{C}\right)$ \\
\hline $\mathrm{G}^{\mathrm{a}}$ & significant & 2320 & +1020 \\
$\mathrm{H}^{\mathrm{a}}$ & intermediate & 400 & +800 \\
$\mathrm{I}^{\mathrm{a}}$ & minimal & 351 & +377 \\
\hline
\end{tabular}

${ }^{8}$ Films with fairly significant $\mathbf{P t}$ redispersion. 
ner than $100 \AA$ could be used to increase the sensitivity, provided contact is not compromised. The detectors responded to changes in gas type or concentration in less than one second, faster than the time required for a single data-acquisition measurement. In other words, data acquisition was rate limiting, preventing quantification of the actual speed of the sensor response. All of the detectors listed in Tables 1 and 2 responded thermally and chemically to $\mathrm{O}_{2}$ and $\mathrm{H}_{2}$, but only thermally to $\mathrm{CF}_{4}, \mathrm{He}$ and $\mathrm{CO}$. The chemical inertness of the film to $\mathrm{CF}_{4}$ allowed the detection of sub-ppm levels of $\mathrm{O}_{2}$ in the presence of $\mathrm{CF}_{4}$. Hereafter, only the chemical responses will be described, since the sensors were operated at fixed temperatures to compensate for the thermal effects.

Oxygen was detected in the range $10^{-7}-1000$ torr, as seen in Figs. 7 through 9. The data in Figs. 7 and 8 (film resistance of $395 \Omega$ and TCR of $+288 \mathrm{ppm} /$ $\left.{ }^{\circ} \mathrm{C}\right)$ were collected at operating temperatures of 119 and $167^{\circ} \mathrm{C}$, respectively. The Fig. 9 data (resistance of $427 \Omega$ and a TCR of $+348 \mathrm{ppm} /{ }^{\circ} \mathrm{C}$ ) were obtained

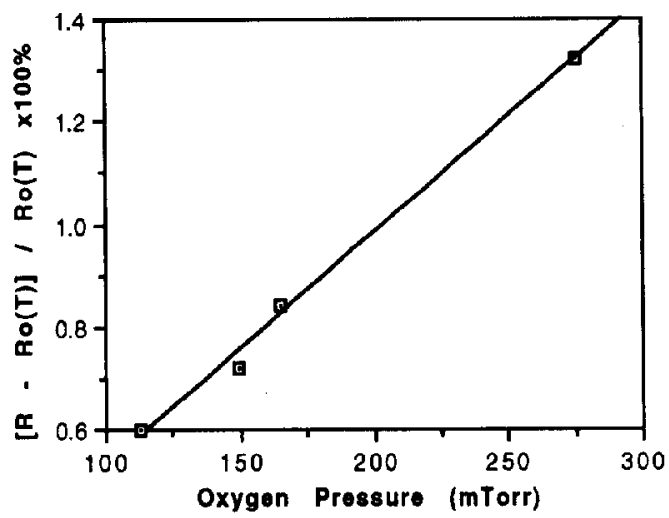

Fig. 7. Percentage resistance change at $119{ }^{\circ} \mathrm{C}$ vs. $\mathrm{O}_{2}$ pressure for detector $\mathrm{A}\left(R_{0}\right.$ of $\left.395 \Omega\right)$.

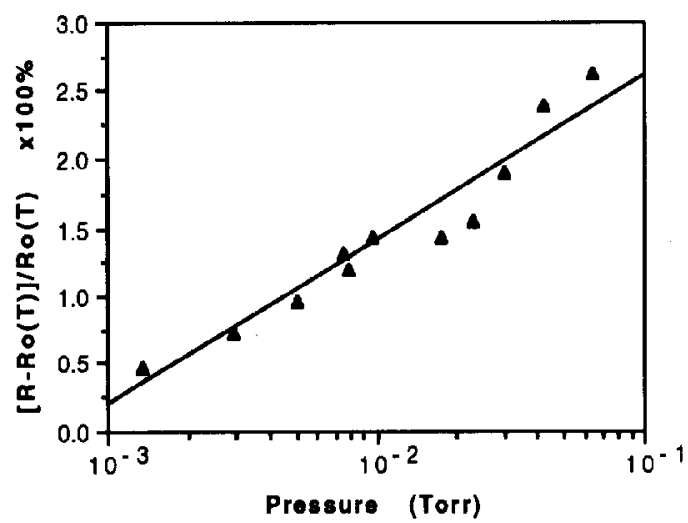

Fig. 8. Percentage resistance change at $167^{\circ} \mathrm{C}$ vs. $\mathrm{O}_{2}$ pressure for detector A $\left(R_{0}\right.$ of $\left.395 \Omega\right)$.

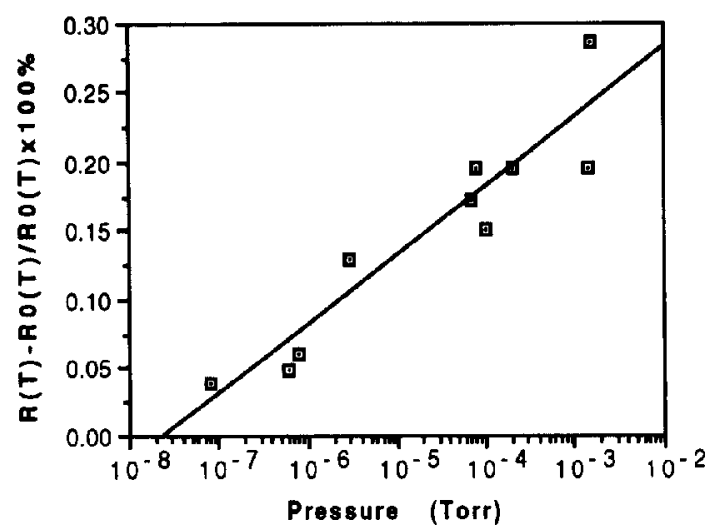

Fig. 9. Percentage resistance change at $150^{\circ} \mathrm{C}$ vs. $\mathrm{O}_{2}$ pressure for detector $A\left(R_{0}\right.$ of $\left.427 \Omega\right)$.

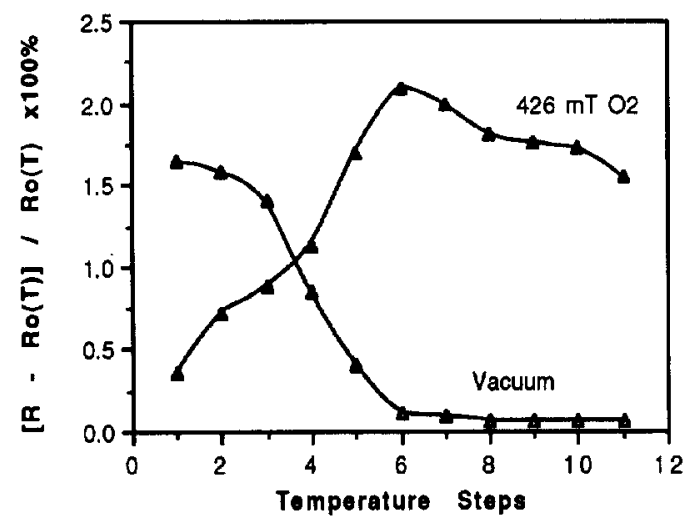

Fig. 10. Percentage resistance change in $\mathrm{O}_{2}$ and vacuum vs. temperature steps for an oxygen cycle of $150{ }^{\circ} \mathrm{C}$ followed by a cycle in vacuum. Each step represents $25^{\circ} \mathrm{C}$, where steps $1-5$ are increasing from 25 to $150^{\circ} \mathrm{C}$, and steps $6-11$ are decreasing back to $25^{\circ} \mathrm{C}$ (detector $\mathrm{A}$ ).

at $150^{\circ} \mathrm{C}$. In each case, the data are shown with respect to $R_{0}(T)$, which is the film resistance in vacuum at the temperature of interest. The best vacuum achieved during these experiments was $8 \times 10^{-8}$ torr, which defined, a priori, the lowest possible detection level. Although the detectors quantified $\mathrm{O}_{2}$ throughout this range, the resolution was best in the $10^{-4}-10^{-1}$ torr range. Based on the detection mechanism (adsorption), the range of greatest accuracy can likely be predetermined either via the amount of transducing material or the available surface area for adsorption. There will be a trade-off between the available adsorption sites and the resulting sensitivity once the films are thick enough to be continuous.

Temperature-programmed desorption (TPD) of $\mathrm{O}_{2}$ was demonstrated with these $\mathrm{Ti}$ and $\mathrm{Pt}$ films. Cycling the temperature in the presence of $\mathrm{O}_{2}$ in $25^{\circ} \mathrm{C}$ steps with a step duration of approximately $20 \mathrm{~s}$ from 25 to $150{ }^{\circ} \mathrm{C}$ and back (Fig. 10) revealed hysteresis in the 
resistance change on the downward cycle. This suggested either a slow equilibration, or an accumulation of oxygen at the surface at higher temperatures that was not subsequently desorbed at lower temperatures. During a second cycle, this time in vacuum, the detector barely recovered at $25^{\circ} \mathrm{C}$, whereas temperatures above $100{ }^{\circ} \mathrm{C}$ enhanced the rate and extent of recovery. This allowed dynamic flow experiments to be run at $150^{\circ} \mathrm{C}$, since the sensor could continuously recover its adsorption capacity via the on-going desorption of the species already on the surface. When the device was operated continuously at lower temperatures, the film resistance did not track concentration or pressure in real time because of accumulated surface oxygen. In terms of long-term stability when operated at $150^{\circ} \mathrm{C}$, the detector exhibited no memory effects during hundreds of temperature and gas cycles.

This temperature dependence of the adsorption-desorption mechanisms can be further investigated by extracting the film's activation energy of conductance. This has its basis in the relationship

$$
\ln \left[G(T) / G_{0}(T)\right]=-E_{\mathrm{G}} / k T
$$

where $G$ corresponds to the conductance at the temperature of interest, $G_{0}$ is the reference conductance, $E_{\mathrm{G}}$ is the activation energy of conduction, $k$ is the Boltzmann constant and $T$ is the temperature, so a plot of $\ln \left[G(T) / G_{0}(T)\right]$ versus $1 / T$ reveals $E_{o}$ from the slope. The data are plotted in this manner in Fig. 11 for four different oxygen pressures. The kinds in these curves indicate difering conduclion mechanisms depending on the temperature. In each case, the curves appear to have two regimes: one corresponding to the

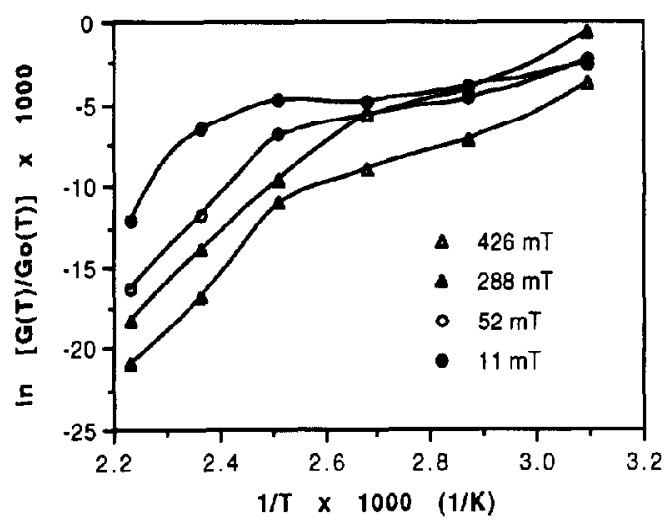

Fig. 11. Natural logarithm of the ratio of the conductance in various oxygen partial pressures to the conductance in vacuum vs. reciprocal temperature. If curves were linear, the slope would correspond to the activation energy of conduction. The nonlinearity indicates that more than one conduction mechanism was involved. $100-150^{\circ} \mathrm{C}$ range and the other to the $25-100^{\circ} \mathrm{C}$ range, which correlates well with the experimental evidence from TPD.

The differing film pretreatment histories also resulted in a variety of gas-sensing characteristics. An example of sensitivity differences is shown in Fig. 12. A responsetime comparison was difficult, since most of the detectors responded more quickly than the data-acquisition system $(<1 \mathrm{~s})$. In many cases, the recovery times were also too small to be quantified. Figure 13 shows the response of a particularly slow detector to a step change in oxygen concentration. The time constant of the response, $\tau$, is defined to allow comparison of various detectors as in Fig. 14. The higher-resistance detectors behaved like conventional semiconducting oxide detectors with high sensitivity, but also with the time-dependent problems of slow response, hysteresis, and long-term drift.

The differences in electrical and sensing characteristics suggested microstructural differences were also present. Scanning tunneling microscopy (STM) was

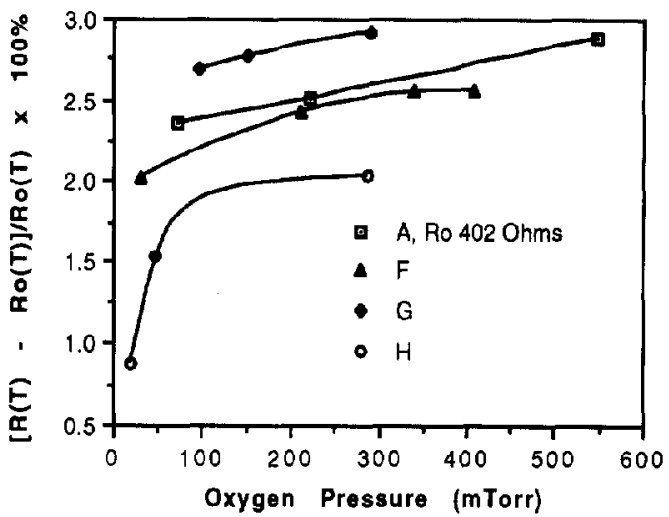

Fig. 12. Percentage resistance change vs. $\mathrm{O}_{2}$ pressure at $150^{\circ} \mathrm{C}$ for detectors $A, F, G$, and $H$, further illustrating differences in sensitivity to oxygen.

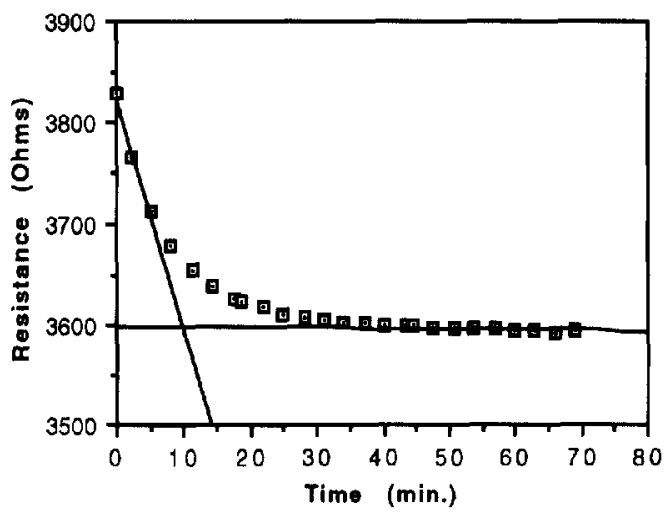

Fig. 13. Resistance vs. time data at $150{ }^{\circ} \mathrm{C}$ for sensor $\mathrm{F}$, one of the extremely slow films, for $\tau$ calculation demonstration purposes. 


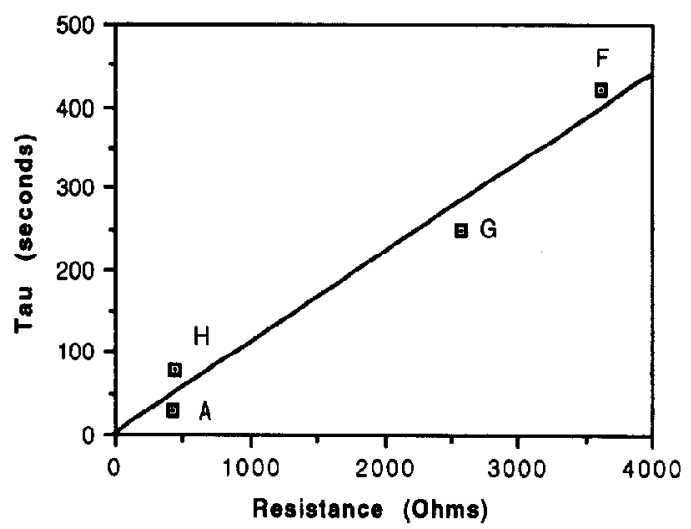

Fig. 14. Time constant ( $\tau$ ) vs. resistance for 285 mtorr $O_{2}$ at $150{ }^{\circ} \mathrm{C}$ for sensors $\mathrm{A}, \mathrm{F}, \mathrm{G}$, and $\mathrm{H}$. The time constant is used as a measure of the initial response speed and the time required to reach equilibrium.

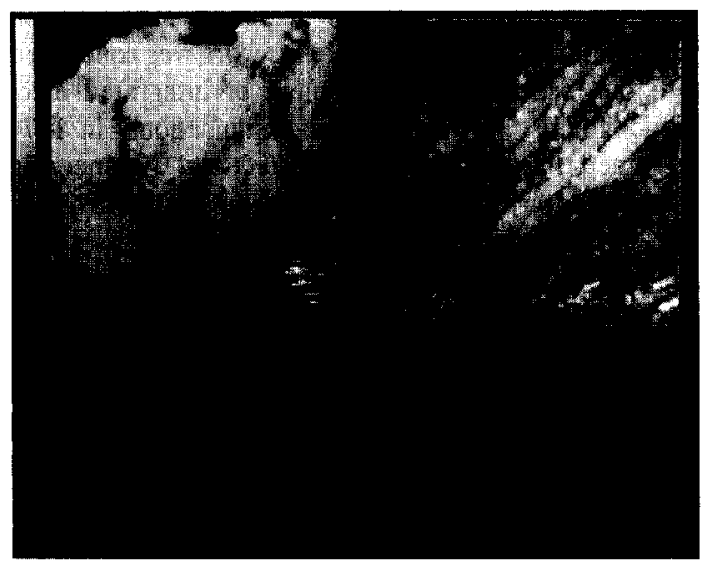

Fig. 15. STM scan comparison of the respective unique features found in a $0.8 \mu \mathrm{m} \times 0.8 \mu \mathrm{m}$ region of a good performing detector (H) (right) and a poor detector (F) (left). Detector $\mathrm{H}$ has a much smaller grain size with striations aligned along the direction of the meandering heater lines below the window.

chosen for preliminary characterization, since a nondestructive area-specific method was required. A poorperforming detector $(F)$ and a good performer (detector H) were compared for possible microstructural differences. The photographs taken of $0.8 \mu \mathrm{m}$ by $0.8 \mu \mathrm{m}$ regions are shown in Fig. 15. Although the detectors had some microstructural characteristics in common, these photographs represent features that were unique to each detector. In Fig. 15, the diagonally-striated pattern on the good detector is parallel to the deep boron-diffused heater lines, which suggests that the electrode thin-film orientation could significantly impact on both the film resistance and the device sensitivity. Based on the conducting and non-conducting regions in this Figure, it would also suggest a higher metal dispersion in the good performer, but it should be noted that the contributions of $\mathrm{Ti}$ and $\mathrm{Pt}$ cannot be separated.

\section{Conclusions}

An ultra-thin-film gas detector [11-13] has been developed with characteristics of high sensitivity, high selectivity, rapid response time, and the absence of long-term reliability problems. An appropriately pretreated transducing film of $\mathrm{Ti}$ and $\mathrm{Pt}$ was sensitive to oxygen over a range of 10 orders of magnitude in pressure and was stable over hundreds of temperature and gas cycles. The detector was chemically inert to $\mathrm{CF}_{4}$, thereby enhancing selectivity for the detection of small quantities of $\mathrm{O}_{2}$ in $\mathrm{CF}_{4}$. Temperature-programmed desorption (TPD) was demonstrated and shown to be an essential part of dynamic measurements. A variety of films with differing electrical, gas sensing and microstructural characteristics was created from the asdeposited films with appropriate pretreatments.

\section{Acknowledgements}

The authors gratefully acknowledge the support of the Semiconductor Research Corporation for this research under contract SRC-89-MC-085.

\section{References}

1 I. Lundström, S. Shivaraman, C. Svensson and L. Lundkvist, A hydrogen-sensitive MOS field-effect transistor, Appl. Phys. Lett., 26(2) (1975) 55-57.

2 K.I. Lundström, M.S. Shivaraman and C.M. Svensson, A hydrogen-sensitive Pd-gate MOS transistor, J. Appl. Phys., 46 (1975) 3876-3881.

3 T. Potcat and B. Lalevic, Transition metal-gate MOS gaseous detectors, IEEE Trans. Electron Devices, ED-29 (1982) 123-129.

4 F. Winquist, A. Spetz, M. Armgarth, A. Nylander and I. Lundström, Modified palladium metal-oxide-semiconductor structures with increased ammonia gas sensitivity, Appl. Phys. Lett., 43 (1983) 839-841.

5 G.J. Maclay, MOS hydrogen sensors with ultrathin layers of palladium, IEEE Trans. Electron Devices, ED-32 (1985) 1158-1164.

6 I. Lundström, M. Armgarth, A. Spetz and F. Winquist, gas sensors based on catalytic metal-gate field-effect devices, Sensors and Actuators, 10 (1986) 399-421.

$7 \mathrm{~K}$. Jelley and G.J. Maclay, A dual-mechanism carbon-monoxide and hydrogen sensor utilizing an ultrathin layer of palladium, IEEE Trans. Electron Devices, ED-34 (1987) 2086-2097.

8 T. Fare, M. Spetz, M. Armgarth and I. Lundström, Quasistatic and high frequency $C(V)$-response of thin platinum metal-oxide-silicon structures to ammonia, Sensors and ACtuators, 14 (1988) 369-386. 
9 G.J. Maclay, K.W. Jelley, S. Nowroozi-Esfahani and M. Formosa, The response of MOS sensors with ultrathin palladium gates to carbon monoxide and methane, Sensors and Actuator, 14 (1988) 331-348.

10 I. Lundström, R. Erlandsson, U. Frykman, E. Hedborg, A. Spetz, H. Sundgren, S. Welin and F. Winquist, Artificial 'olfactory' images from a chemical sensor using a light-pulse technique, Nature, 352 (1991) 47-50.

11 C.L. Johnson, K.D. Wise and J.W. Schwank, A thin-film gas detector for semiconductor process gases, Digest IEEE IEDM, San Francisco, CA, Dec. 1988, pp. 662-666.

12 C.L. Johnson, J.W. Schwank and K.D. Wise, Ultra-thin film gas detector, US Patent No 4953387 (4 Sept., 1990).

13 C.L. Johnson, Ultra-thin film monolithically-integrated siliconbased gas detectors, Ph.D. Dissertation, University of Michigan, September 1990.

\section{Biographies}

Christy L.Johnson received her B.S. degree in chemical engineering from Purdue University, West Lafayette, $\mathrm{IN}$, in 1985, and her M.S. and Ph.D. degrees in chemical engineering from the University of Michigan, Ann Arbor, MI, in 1986 and 1990, respectively. From 1986 through 1990 she was an SRC graduate fellow. She also held a DuPont Chemical Engineering Ph.D. Fellowship during her graduate studies. She is currently a staff engineer/scientist at IBM Corporation, Burlington, VT, working on various sensors (including gas detectors) and their application to advanced real-time semiconductor process control.

Johannes Schwank reccived his Ph.D. in physical chemistry from the University on Innsbruck, Austria, in 1978. He joined the Department of Chemical Engineering at the University of Michigan, Ann Arbor, where he is now professor and chairman. He also serves as director of the Center for Catalysis and Surface Science. Dr Schwank is the author of over 60 technical publications, including three US patents, and he has presented more than 70 papers at national and international conferences. He is a member of numerous professional societies, including the American Institute of Chemical Engineers, the American Socicty for the Advancement of Science, the Materials Research Society, and the Royal Society of Chemists London. His present research interests include microlectronic gas sensors, heterogeneous catalysis, surface science, and fuel-cell technology.

Kensall D. Wise received the BSEE degree with highest distinction from Purdue University in 1963 and the M.S. and Ph.D. degrees in electrical engineering from Stanford University in 1964 and 1969, respectively. From 1963 to 1965 (on leave 1965-1969) and from 1972 to 1974, he was a member of technical staff at Bell Telephone Laboratories, where his work was concerned with the exploratory development of integrated electronics for use in telephone communications. In 1974 he joined the Department of Electrical Engineering and Computer Science at the University of Michigan, Ann Arbor, where he is now serving as professor and director of the Center for Integrated Sensors and Circuits. Dr Wise served as general chairman of the 1984 IEEE Solid-State Sensor Conference, as technical program chairman of the 1985 International Conference on Solid-State Sensors and Actuators, and as IEEE-EDS National Lecturer for 1986. He is a fellow of the IEEE. His present research interests focus on the automated manufacturing of integrated circuits and on the development of solid-state sensors for health care, transportation, and industrial process control. 